\title{
OCORRÊNCIA DE PARASITOS GASTRINTESTINAIS EM AVES SILVESTRES NO MUNICÍPIO DE SEROPÉDICA, RIO DE JANEIRO, BRASIL
}

\author{
Ísis Alves Costa, ${ }^{1}$ Cleide Domingues Coelho, ${ }^{1}$ Camila Bueno,${ }^{3}$ Ildemar Ferreira ${ }^{4}$ E \\ Ronald Bastos Freire ${ }^{5}$ \\ 1. Pós-graduandas em Ciências Veterinárias, Departamento de Parasitologia Animal, Instituto de Veterinária da \\ Universidade Federal Rural do Rio de Janeiro \\ 2. Aluna de Graduação em Ciências Biológicas da Universidade Federal Rural do Rio de Janeiro \\ 3. Professor associado da Universidade Federal Rural do Rio de Janeiro, Laboratório de Ornitologia \\ 4. Professor associado da Universidade Federal Rural do Rio de Janeiro.
}

RESUMO

Este estudo buscou evidenciar o papel das enteroparasitoses como fator adicional de pressão biológica sobre as espécies de aves silvestres locais e migratórias. A ocorrência de endoparasitos pode ser considerada como indicador de alterações indesejáveis das condições higiênicas, acarretando diminuição das áreas naturais com comprometimento dos locais de descanso e da qualidade do hábitat utilizado como ponto de alimentação aviária. Setenta e cinco amostras fecais foram coletadas no câmpus da Universidade Federal Rural do Rio de Janeiro (UFRRJ), Brasil, entre agosto 2007 e maio 2008, e analisadas em lugol e pela técnica de Faust.
Das amostras analisadas, $82,66 \%$ foram positivas para parasitas entéricos, 44\% parasitados por tricomonadídeos, 5,33\% com o gênero Chilomastix, $52 \%$ com oocistos de coccídeos, $29,33 \%$ por formas vegetativas de Entamoeba coli, 37,33\% com Iodamoeba butschlii e 10,66\% com ovos de helmintos. A elevada prevalência de enteroparasitas indica a necessidade de estudos mais detalhados e avaliações mais frequentes de saneamento deste hábitat, cujo impacto parece estar associado às precárias condições higiênicas locais decorrentes da crescente antropização na região.

PALAVRAS-CHAVES: Aves silvestres, enteroparasitos, impacto ambiental.

\section{ABSTRACT}

\section{GASTRINTESTINAL PARASITIC OCCURRENCE IN WILD BIRDS CAPTURED IN SEROPEDICA CITY AT RIO DE JANEIRO STATE, BRAZIL}

This study aimed to assess the role of endoparasitic infections as another factor of biological pressure on both migratory and local bird species. The occurrence of endoparasites may be considered a sign of undesirable hygienic alterations, causing the shortening of natural fields, compromising the resting area and the habitat nutritional quality. A total of 75 fecal samples were collected at the Campus of the Universidade Federal Rural do Rio de Janeiro (UFRRJ), Brazil, between August 2007 and May 2008, and they were analyzed in a Lugol's solution by Faust's technique. Amongst the $82.66 \%$ positive samples for enteric parasites, $44 \%$ were parasitized by the trichomonads and $5.33 \%$ by the Chilomastix enterozoary genera, $52 \%$ presented coccidian oocysts, $29.33 \%$ showed Entamoeba coli, 37.22\% presented Iodamoeba butschlii vegetative forms, and $10.66 \%$ were positive for worm eggs. The high prevalence of enteroparasites observed indicates the need of more detailed and frequent evaluations of the environmental sanitary conditions, whose impact seems to be associated to the scarce local hygienic conditions due to the growing anthropization.

KEYWORDS: Enteroparasites, environmental impact, wild birds. 


\section{INTRODUÇÃO}

O parasitismo é uma condição em que dois organismos, um hospedeiro e um parasito, desenvolvem uma relação direta e estreita na qual o agente parasitário depende de algum elemento naturalmente produzido pelo indivíduo infectado para manter seu ciclo biológico (LEDERBERG, 1998). Com isso, os parasitos desenvolvem estágios diferenciados em função da disponibilidade de alimentos em tecidos, humores e constituintes gerados pelo hospedeiro, estabelecendo assim um relacionamento essencialmente nutricional (LEDERBERG, 1998), sendo o hospedeiro importante para manutenção das características bióticas das formas parasitárias disponíveis no ambiente. Assim, as alterações no ecossistema podem afetar tanto parasitas em suas fases de vida livre quanto os hospedeiros e vetores que, por se tornarem mais resistentes ou tolerantes, exercem uma contrapressão biológica capaz de levar à extinção ou à modificação das populações parasitárias presentes no ambiente (LEDERBERG, 1998; BRADLEY \& ALTIZER, 2006), e assim determinar, desse modo, a emergência e/ou reemergência de doenças parasitárias capazes de pôr em risco a saúde animal e do homem. Este aspecto pode ser evidenciado pela relação das condições sanitárias do ambiente e o declínio das populações avícolas em diversos biomas de todo o mundo (REED et al., 2003).

Dentre os problemas sanitários que afetam as aves silvestres, as enfermidades parasitárias importam não só pela frequência com que ocorrem, mas também pela potencialidade de estarem relacionadas às graves infecções ou até mesmo à morte de considerável parte da avifauna presente em uma região densamente parasitada (REED et al., 2003; MARIETTO et al., 2009). A prevalência de infecções parasitárias e, em particular, das endoparasitoses, está diretamente relacionada ao comportamento, nutrição e desenvolvimento reprodutivo das aves silvestres, causando um déficit na densidade populacional. Isso porque propicia o aparecimento de infecções secundárias, como o surgimento de enterite hemorrágica, abscesso no tecido subcutâneo, hepático, pulmonar, infecções causadas por organismos que atinjam a corrente sanguínea, acometendo outros tecidos, incluindo pulmões, fígado, baço, rins, intestinos, musculatura esquelética e até mesmo cérebro (FREITAS et al., 2002; MARIETTO et al., 2009), resultando em graves consequências sobre a conservação das espécies avícolas e, em especial, daquelas ameaçadas de extinção.

Além disso, as endoparasitoses que acometem a avifauna são de grande importância para a saúde pública, pois podem significar o agravamento de problemas econômicos, sociais, médicos e ambientais, sobretudo nos países em desenvolvimento. Isto se deve à dispersão resultante dos diferentes endoparasitos causadores de uma ampla diversidade de zoonoses disponibilizadas em um hábitat destruído, fragmentado ou mesmo ocupado de forma inadequada pela população humana, caracterizando um ambiente antropizado (DASZAK et al., 2001).

O parasito, o hospedeiro e o meio ambiente são três fatores primordiais intimamente relacionados com as infecções parasitárias. Por conta disso, os inquéritos coproparasitológicos, que inicialmente (até a década de 1970) eram focalizados em infecções em seres humanos, cederam espaço e atenção às análises de frequência de parasitismo em espécies animais exóticos (FERREIRA et al., 1994; BUNBURY et al., 2008). Neste contexto, as aves ganharam destaque, por sua diversidade nos diferentes espaços geográficos que ocupam.

Atualmente, as avaliações epidemiológicas do parasitismo em diferentes espécies aviárias originam resultados de maior valia quando se deseja comparar parasitas e seus hospedeiros infectados, em função das alterações do meio ambiente (DASZAK et al., 2000; BUNBURY et al., 2008).

Em relação às criações extensivas e à produção avícola, as protozooses intestinais representam grande impacto em termos de custo-benefício, com efeitos deletérios à saúde dos indivíduos, sobretudo ao atingir criadouros avícolas ou mesmo outros animais de produção que entrem em contato com aves silvestres naturalmente infectadas, independentemente da tolerância ou resistência ao parasitismo (McCALLUM \& DOBSON, 2002).

Embora existam diversos programas de prevenção do parasitismo destinados aos seres humanos com projeções teóricas de controle das parasitoses intestinais em diferentes países, infelizmente, constata-se um descompasso entre o êxito alcançado nas nações mais desenvolvidas e aquele verificado nas economias mais pobres, onde a economia, a educação e as condições ambientais são barreiras quase que intransponíveis a serem derrubadas. Com isso, há o claro comprometimento da 
saúde humana, da preservação de espécies animais e das condições higiênico-sanitárias do ambiente. Assim, é de extrema relevância que se realizem estudos epidemiológicos e prospectivos buscando maiores informações sobre o impacto causado pelo crescimento desordenado das áreas urbanas, assim como aquele decorrente da urbanização das áreas rurais e reservas florestais, capazes de pôr em risco a própria saúde humana, além de causar prejuízos à produção animal e à biologia das espécies vivas, tanto parasitárias como de animais silvestres sob risco de extinção e/ou modificação comportamental por conta da falta de alimentos disponíveis e do esgotamento inerente à degradação e antropização ambientais (DASZAK et al., 2000; SLIFKO et al., 2000; SLEEMAN, 2006).

O presente estudo foi realizado com o intuito de se estabelecer uma provável correlação entre parasitas, hospedeiro e ambiente. Para tanto, desenvolveu-se uma análise prospectiva coproparasitológica das aves silvestres capturadas no ambiente do câmpus da Universidade Federal Rural do Rio de Janeiro, Seropédica, RJ, Brasil, nos períodos de agosto de 2007 (inverno) e de maio de 2008 (outono).

\section{MATERIAL E MÉTODOS}

Área de estudo

Como local de estudo, foi utilizado o lago do Instituto de Biologia, pertencente à Universidade Federal Rural do Rio de Janeiro (UFRRJ) (22\%44'38” S; $43^{\circ} 42^{\prime} 27^{\prime}$ 'W).

Captura das aves

Aves silvestres pertencentes às ordens Passeriformes, Cuculiformes e Columbiformes foram capturadas no período de agosto de 2007 a maio de 2008 em redede-neblina, armadas entre os períodos da manhã e o crepúsculo. As aves capturadas em rede-de-neblina eram rapidamente coletadas, colocadas em sacos de pano, contendo papel absorvente em seu interior, e postas em descanso até que estas defecassem. As aves capturadas eram marcadas cortando-se penas estratégicas da asa, normalmente primárias, para eventual notificação da recaptura do dia, evitando, assim, falsos-negativos em cada campanha.
Identificação das espécies avícolas

A identificação das aves silvestres capturadas foi realizada pelo Dr. Ildemar Ferreira, responsável pelo Laboratório de Ornitologia do Instituto de Biologia da UFRRJ.

Classificação das espécies avícolas

A classificação das aves silvestres capturadas foi realizada com auxílio da bibliografia do CBRO (2009).

\section{Amostras fecais}

Foram analisadas 75 amostras fecais que, após a coleta, eram acondicionadas em frascos de $50 \mathrm{~mL}$ contendo solução $2,5 \%$ de dicromato de potássio $\left(\mathrm{K}_{2} \mathrm{Cr}_{2} \mathrm{O}_{7}\right)$, que impede a proliferação de fungos e bactérias nas amostras fecais. As amostras eram enviadas ao Laboratório de Toxicologia Ambiental e Imunologia Parasitária do Departamento de Biologia Animal da UFRRJ. As amostras foram mantidas tanto à temperatura ambiente $\left(23^{\circ} \mathrm{C}\right.$ a $\left.24^{\circ} \mathrm{C}\right)$ quanto sob refrigeração $\left(4^{\circ} \mathrm{C}\right.$ a $\left.10^{\circ} \mathrm{C}\right)$ até a realização das análises parasitológicas.

Identificação dos parasitos

O diagnóstico dos parasitos foi realizado por meio dos seguintes procedimentos: exame direto a fresco realizado ao microscópio ótico com lugol, objetivando o encontro de trofozoítos; técnica de centrífuga-flutuação em solução de sacarose (com densidade de 1,3g/mL) para pesquisa de cistos nas amostras; identificação dos parasitos por meio de dados morfológicos obtidos, analisados com auxílio da bibliografia.

\section{RESULTADOS}

Foram capturadas 75 aves sendo 92\% Passeriformes, 6,66\% Columbiformes e 1,33\% Cuculiformes. As espécies, bem como o número de indivíduos de cada espécie de ave capturada e seus respectivos nomes populares, estão na Tabela 1 .

Observou-se parasitismo em $82,66 \%$ das espécies de aves capturadas. Das amostras fecais positivas, tricomonadídeos (88\%) e Iodamoeba butschlii $(74,66 \%)$ foram os parasitas mais prevalentes. A ocorrência de endoparasitos, no entanto, correspondeu a uma fre- 
quência relativa de $58,66 \%$ de oocistos de coccídeos e $44 \%$ de trofozoítas de tricomonadídeos. As espécies Entamoeba coli e I. butschlii foram, respectivamente, encontradas em $29,33 \%$ e $37,33 \%$ das amostras fecais. Os endoparasitos de menor frequência foram do gênero Chilomastix, $(5,33 \%)$ e ovos de helmintos (10,66\%).

TABELA 1. Relação quantitativa das ordens e espécies, com os respectivos nomes populares, das aves silvestres capturadas no câmpus da UFRRJ, em rede de neblina (mist-net), no período de agosto 2007 a maio de 2008

\begin{tabular}{|c|c|c|c|}
\hline Ordem & Nome científico & Nome vulgar & $\begin{array}{l}\mathrm{N}^{\mathrm{o}} \text { de indivíduos } \\
\text { capturados }\end{array}$ \\
\hline Passeriformes & Agelaius ruficapillus, Vieillot, 1819 & Garibaldi & 20 \\
\hline Passeriformes & Certhiaxis cinnamomea (Gmelin, 1788) & Curutié & 1 \\
\hline Passeriformes & Elaenia flavogaster (Thumberg, 1822) & Maria-é-dia & 7 \\
\hline Passeriformes & Estrilda astrild (Lin, 1766) & Bico de lacre & 4 \\
\hline Passeriformes & Fluvicola nengeta (Lin, 1766) & Lavadeira mascarada & 1 \\
\hline Passeriformes & Furnarius rufus (Gmelin, 1788) & João de barro & 1 \\
\hline Passeriformes & Lepdocolaptes angustirostris (Viellot, 1818) & Arapaçú do cerrado & 2 \\
\hline Passeriformes & Molothrus bonariensis (Gmelin, 1789) & Maria preta & 12 \\
\hline Passeriformes & Notiochelidon cyanoleuca (Vieillot, 1817) & Andorinha pequena & 2 \\
\hline Passeriformes & Notiochlidon cyanoleuca (Vieillot, 1817) & Andorinha & 2 \\
\hline Passeriformes & Progne chalybea (Gmelin, 1789) & Andorinha azul & 1 \\
\hline Passeriformes & Sicalis flaveola (Lin, 1766) & Canário da terra & 7 \\
\hline Passeriformes & Stelgidopteryx ruficollis (Vieillot, 1817) & Andorinha serradora & 4 \\
\hline Passeriformes & Thraupis sayaca, Linnaeus, 1766 & Sanhaço & 1 \\
\hline Passeriformes & Turdus albicollis, Vieillot, 1818 & Sabiá coleira & 1 \\
\hline Passeriformes & Turdus amaurochalinus Cabanis, 1851 & Sabiá poca & 2 \\
\hline Passeriformes & Tyrannus melancholicus, Vieillot, 1819 & Suiriri & 1 \\
\hline Cuculiformes & Crotophaga ani, Linné, 1758 & Anu preto & 1 \\
\hline Columbiformes & Columbina talpacoti $($ Temminck, 1811) & Rolinha comum & 5 \\
\hline
\end{tabular}

\section{DISCUSSÃO}

A fragmentação de áreas naturais causa a diminuição da qualidade e da quantidade de recursos ambientais, induzindo as espécies de aves silvestres a buscarem novos locais de refúgio, abrigo, alimentação e nidificação, com repercussões sobre os ambientes urbanos mais próximos. Assim, elegem "poleiros" em praças, parques e jardins botânicos, em nichos que não lhes foram destinados, ou planejados, originalmente.

Em decorrência da degradação ambiental como resultado da antropização de hábitats, há uma crescente necessidade de se estabelecerem medidas que permitam análise da impactação ambiental. Um dos resultados dessa fragmentação é a perda da riqueza de espécies da avifauna (VALADÃO et al., 2006). Em termos de conservação, é importante que se conheçam as espécies presentes em um dado local e as interações estabelecidas entre elas, uma vez que a integridade do meio é dependente dessa diversidade e do equilíbrio das espécies existentes no ambiente (KIRWAN et al., 2001; MATHEWS, 2009).

Assim, as enteroparasitoses representam uma pressão considerável para aves silvestres, em que seu autoíndice denota um agravamento do desequilíbrio ecológico do local que essas aves habitam, podendo ser associado à rápida diminuição das áreas naturais e à qualidade higiênica (VALADÃO et al., 2006; MARIETTO et al., 2009).

Aves são consideradas ideais para avaliar os efeitos das pressões ambientais, representadas principalmente pelas atividades agropecuárias, pois são diversificadas e conspícuas, além de se constituírem em indicadores sensíveis da degradação ambiental (DASZAK et al., 2000; VALADÃO et al., 2006). Quando se trata de aves migratórias, podem-se ainda avaliar ambientes distintos com uma única espécie como instrumento de estudo.

A avaliação da qualidade do hábitat por meio das áreas de descanso, utilizadas como ponto de alimentação, permite que os inquéritos parasitológicos da 
ocorrência de enteroparasitoses possam ser utilizados como parâmetro de avaliação para as condições sanitárias do ecossistema, assim como do grau de regeneração ambiental. $\mathrm{O}$ hábito alimentar do hospedeiro influencia diretamente a composição da sua fauna parasitária, segundo relato de MARIETTO et al. (2006), assim como as associações existentes entre as espécies de parasitas (MATHEWS, 2009).

A ocorrência de endoparasitos encontrados nas amostras fecais de aves silvestres está representada na Figura 1.

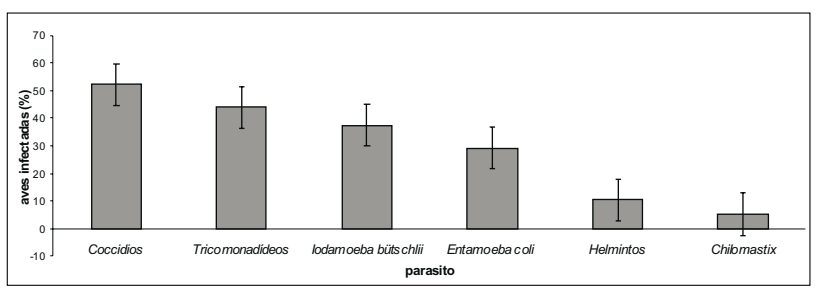

FIGURA 1. Frequência de aves silvestres naturalmente infectadas com endoparasitas.

A alta frequência de Entamoeba coli $(29,33 \%)$ (Figura 2) e de I. butschlii (37,33\%) na avifauna local demonstra o elevado grau de antropização em que se encontra o ambiente estudado. Acredita-se que estas espécies estejam ocupando uma via oportunista de infecção em aves, existindo, assim, a possibilidade de sua transmissão aos seres humanos, pois apesar de não serem consideradas patogênicas, comensais no intestino do homem. É importante salientar que os índices encontrados podem ser utilizados como parâmetros para medir o grau de contaminação fecal a que os indivíduos estão expostos, corroborando as informações de GRACZYK (2008).

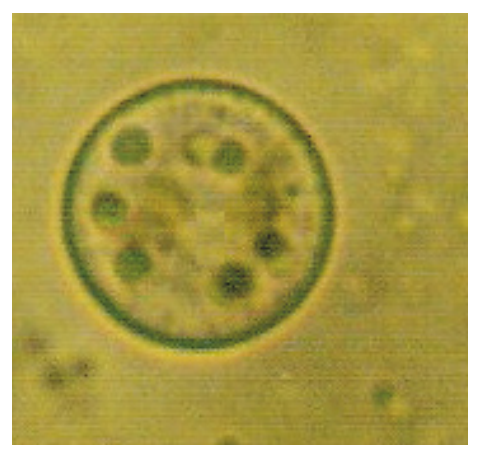

FIGURA 2. Cisto de Entamoeba coli. Aumento de 1000x. Fonte: Ísis Costa.
Com as amostras fecais do garibaldi, Agelaius ruficapillus, foi possível construir um paralelo entre as espécies de amebas encontradas e o hábitat ocupado pelo hospedeiro, pois, segundo Graczyk et al. (2008), um dos principais mecanismos de transmissão dos protozoários se dá por meio da água contaminada. Isso explicaria o alto índice de contaminação pelos parasitos, já que a espécie de Passeriforme está intimamente ligada à água. Além de alimentar-se de insetos e grãos que apanha na vegetação palustre, segundo relatos de PORTO \& PIRATELLI (2005), seu ninho, em forma de tigela, é geralmente construído entre as folhas de taboas, que é o ambiente encontrado no local de coleta das amostras.

As aves capturadas durante o mês de agosto apresentavam placa de incubação, indicando estar em época reprodutiva, fato que não se repetiu nas aves observadas no mês de maio.

$\mathrm{O}$ alto desgaste, tanto pela fase reprodutiva de todas as aves capturadas em agosto como pela migração de algumas delas, na mesma época, parece levar a um estresse imunitário e este a uma maior susceptibilidade ao parasitismo, corroborando informações de MARIETTO et al. (2009). É possível correlacionar o parasitismo perfeitamente com a alta demanda energética requerido pelas aves, comparando-se nos dois momentos de captura (entre agosto/2007 e maio/2008). A maioria das infecções parasitárias intestinais é assintomática. Geralmente os animais jovens são mais frequentemente e gravemente parasitados (FREITAS et al., 2002).

Em maio, capturaram-se muitos indivíduos jovens, o que demonstra a importância da qualidade dos hábitats utilizados como ponto de reprodução. Uma das formas de disseminação de parasitos pode se dar dos pais para os filhos, em que as aves jovens têm acesso ao chão e ficam expostas aos excrementos dos demais animais (MARIETTO et al., 2009).

Esta análise pode ser perfeitamente observada diante do elevado parasitismo, dado por tricomonadídeos (Figura 3), estando presente em 44\% das amostras analisadas com maior frequência no mês de agosto/2007 e se contrapondo à análise fecal do mês de maio/2008. A disponibilidade de fontes de águas poluídas no estágio reprodutivo, em decorrência do estresse fisiológico das aves, pode ser associada à transmissão de patógenos deste grupo. O maior contato entre os pares reprodutores pode também desempenhar um papel, aumentando a susceptibilidade à infecção 
durante o período reprodutivo, como relatado por BUNBURY (2008).

Os protozoários flagelados tricomonadídeos são extremamente patogênicos para as aves e sua ocorrência indica o declínio de espécies, correspondendo, assim, a um prognóstico ruim em termos de equilíbrio ambiental, para espécies sob ameaça de extinção. Estes flagelados podem atingir o trato digestório alto, como, por exemplo, a orofaringe, causando lesões pseudomembranosas localizadas, principalmente, em aves jovens, e ainda serem disseminados pelo organismo, atingindo diferentes órgãos vitais, segundo informações de VIEIRA et al. (2008).

Uma ave infectada pode ter perda de apetite, vômitos, perda de penas, diarreia, dificuldade na deglutição, dispneia (dificuldade na respiração), perda de peso, e polidpsia (aumento da sede). Excrementos podem ter uma descoloração amarela, que é mais comumente visível na porção branca das fezes. Os jovens são mais frequentemente infectados e podem chegar a óbito. Algumas aves podem ser portadoras assintomáticas (VIEIRA et al., 2008). Em nenhuma das aves positivas para estes flagelados, jovens ou adultas, foram observados sinais clínicos da enfermidade.

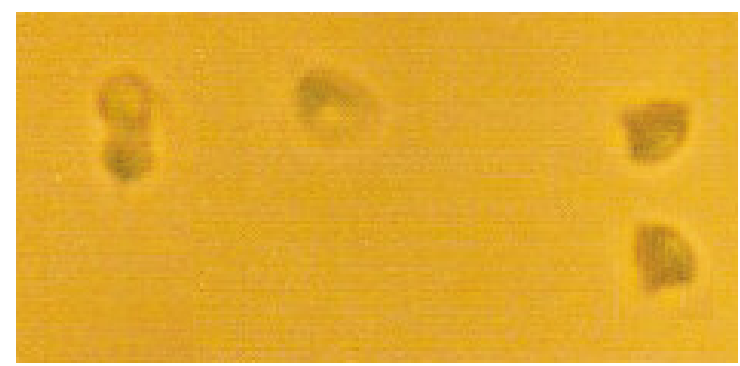

FIGURA 3. Trofozoíto de tricomonadídeos. Aumento de 1000x. Fonte: Ísis Costa.

Coccídeos são uma das mais comuns parasitoses intestinais em aves, estando envolvidos em muitos processos ecológicos onde a transmissão entre os indivíduos ocorre por meio do contato com fezes contaminadas com oocistos esporulados (LÓPEZ et al., 2007). A frequência de $52 \%$ de coccídeos (Figura 4) nas amostras fecais apresentou ligeira queda, quando comparada ao período de agosto de 2007, mas ainda assim manteve um resultado de grande relevância, já que os pássaros adultos podem ser portadores de coccídeos sem apresentarem os sinais da doença (LÓPEZ et al., 2007). Como no mês de maio/2008 a população era constituída por grande número de filhotes decorrente do período reprodutivo indicado em agosto/2007, os coccídeos podem significar um grande problema, ameaçando o equilíbrio populacional da avifauna estudada.

A Figura 5 mostra a ocorrência do parasitismo por coccídeos, no período reprodutivo (agosto/2007) e no período de crescimento dos filhotes (maio/2008), comparada à distribuição do parasitismo por tricomonadídeos.

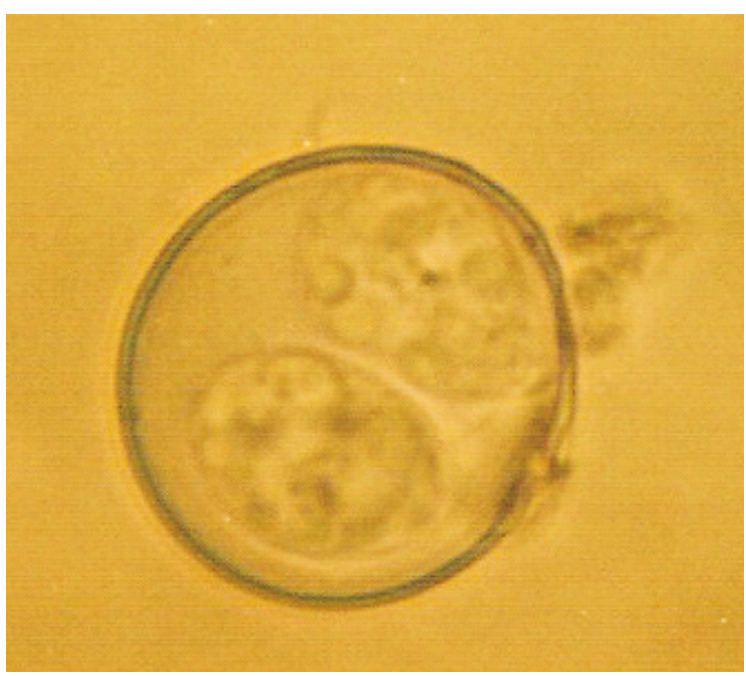

FIGURA 4. Oocisto de coccídio. Aumento 1000x. Fonte: Ísis Costa.

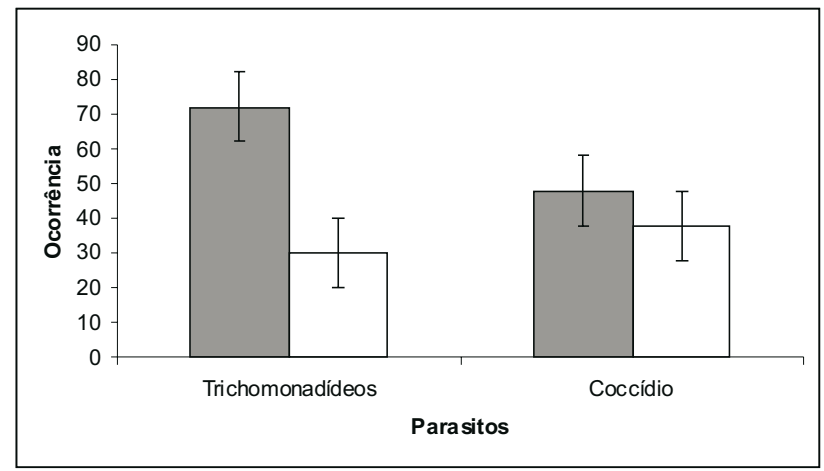

FIGURA 5. Frequência de parasitismo nas amostras fecais de aves silvestres naturalmente infectadas por oocistos de coccídeos e trofozoítos de tricomonadídeos, nos períodos de agosto (colunas cheias) e maio (colunas vazias). 
O nível elevado de parasitas permite inferir que a alta antropização do ambiente não evoluiu juntamente com a qualidade de higienização do ambiente em questão, já que se correlacionou o parasitismo ao hábito alimentar das aves e à possível sobreposição de nichos de algumas delas, dada a grande fragmentação local. Alguns relatórios sugerem que muitas dessas aves adquirem enteropatógenos, em virtude dos seus hábitos alimentares. Numerosas espécies de aves são atraídas por esgotos não tratados, lixo, lixeiras, chorume, e outras fontes de patógenos entéricos (REED et al., 2003).

No ambiente urbano, aves insetívoras e onívoras são representadas, normalmente, por espécies generalistas, conforme preconizado por VILLANUEVA \& SILVA (1996). Além disso, um grande número de insetívoros e onívoros presentes em pequenos fragmentos é esperado, pois esses hábitos alimentares funcionam como "efeitotampão" contra as flutuações no suprimento alimentar, que restringem a ocorrência de frugívoros e nectarívoros, além de insetívoros mais especializados, de acordo com informações de VILLANUEVA \& SILVA (1996).

As aves de hábito onívoro são mais susceptíveis ao parasitismo, pois, ao se alimentarem de insetos e frutos, têm uma maior variedade em sua dieta, ampliando as formas de contágio por enteroparasitas, como demonstrado na Figura 6. Os artrópodes ocupam o papel de vetores para o parasitismo de aves insetívoras, como, por exemplo, o curutié (Certhiaxis cinnamomea), alimentando-se de insetos, que podem ser capturados ainda em voo, sendo menos parasitadas em comparação às aves onívoras e granívoras. Possivelmente, as aves que coletam grãos durante o forrageio, ao revirarem o solo ou fezes de animais em busca de sementes, como a maria-preta (Molothrus bonariensis), acabam aumentando as chances de contaminação por enteroparasitos, não somente pelo hábito alimentar, mas também pelo comportamento parasita da maria-preta, que consiste na postura de ovos no ninho de uma ave de outra espécie, em que a fêmea "hospedeira" encarrega-se de incubar os ovos e criar os filhotes "adotivos" (PORTO \& PIRATELLI, 2005). Esse comportamento, tanto pelo hábito alimentar quanto pelo modo parasita dessas aves, aumenta as chances de dispersão de patógenos para a própria maria-preta e para as aves hospedeiras, que podem vir a se contaminar por meio do contato com as fezes deixadas pela maria-preta no ninho de seus hospedeiros.
Em termos de conservação, é importante que se conheçam as espécies presentes em um dado local e as interações estabelecidas entre elas, uma vez que a integridade do meio é dependente dessa diversidade e do equilíbrio das espécies existentes no ambiente. Os resultados deste estudo concordam com registros prévios feitos por outros grupos de pesquisas em biomas similares (MARIETTO, 2009). Contudo, deve-se considerar a necessidade de um maior número amostral, que confirmaria com maior êxito a abundância relativa do parasitismo nesses animais, muito embora as diferenças marcantes obtidas com os resultados das análises de $I$. butschlii e Entamoeba coli sejam questionáveis e indicativos de antropização pelos quais se devem direcionar maior atenção.

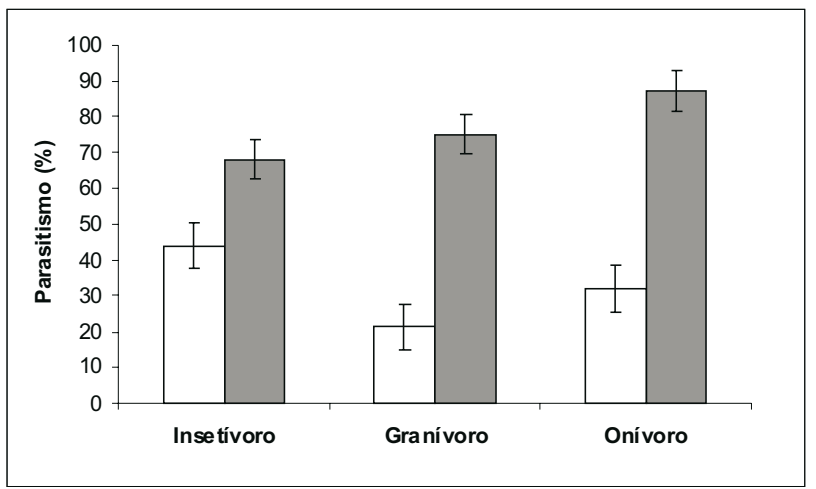

FIGURA 6. Correlação entre o parasitismo (barras negras) e o hábito alimentar (barras brancas) de aves silvestres capturadas.

Embora o presente trabalho não permita uma conclusão definitiva sobre o parasitismo aviário como indicador de espécies em extinção (BUNBURY et al., 2008), a necessidade de particularização das espécies avícolas dentro de um período definido não impediu que se observassem os efeitos do ambiente sobre o parasitismo avícola no local escolhido. Ainda que elevada ocorrência $(\sim 90 \%)$ de endoparasitas nas espécies de aves silvestres indique a necessidade de elas serem avaliadas individualmente, a abundância relativa de parasitas limitantes à sanidade avícola sugere haver uma correlação direta entre a ocorrência desses agentes parasitários e alterações ambientais decorrentes da impactação decorrente da antropização crescente na região estudada.

As práticas de higiene inadequadas, como lançamento de esgoto não tratado, lixo nos hábitats em 
que vivem essas aves, estão intimamente relacionadas ao elevado parasitismo pelo gênero Iodamoeba e por tricomonadídeos (BUNBURY et al., 2008; GRACZYK, 2008). Os parasitos tricomonadídeos são de grande importância no declínio populacional de aves em extinção (BUNBURY et al., 2008; GRACZYK, 2008) e assim como os parasitas da espécie I. butchlii são indicadores de degradação e antropização ambiental. Os resultados do presente estudo corroboraram a hipótese de que os inquéritos parasitológicos podem ser utilizados como parâmetro de risco ambiental, quando se busca avaliar as condições sanitárias do meio ambiente e da avifauna em determinado local.

\section{CONCLUSÕES}

Os resultados dos ensaios prospectivos do presente estudo permitem afirmar que:

- a evidente antropização do local escolhido influenciou significativamente na prevalência das endoparasitoses ocorrentes nas aves silvestres capturadas no câmpus da UFRRJ entre agosto de 2007 e maio de 2008, com flutuação parasitária diretamente relacionada com as condições ambientais e alimentos disponíveis para as aves presentes no hábitat estudado;

- a relação das aves com organismos patogênicos pode gerar numerosos problemas de sanidade acometendo estes animais e, provavelmente, os demais organismos relacionados a estes, dada a presença de parasitos zoonóticos;

- a antropização exerce uma pressão sobre as espécies migratórias, presentemente representadas por andorinhas, que se tornam potenciais vetores de parasitas importantes para o estabelecimento de novos focos endêmicos e para o ressurgimento de surtos de doenças ao longo de suas rotas migratórias.

\section{REFERÊNCIAS}

BRADLEY, C. A.; ALTIZER, S. Urbanization and the ecology of wildlife diseases. Trends in Ecology and Evolution, v. 22, n. 2, p. 95-102, 2006.

BUNBURY, N.; JONES, C. G.; GREENWOOD, A. G.; BELL, D. J. Epidemiology and conservation implications of Trichomonas gallinae infection in the endangered Mauritian pink pigeon. Biological Conservation, v. 141, n. 1, p. $153-161,2008$.
COMITÊ BRASILEIRO DE REGISTROS ORNITOLÓGICOS. Listas das aves do Brasil. Versão 9/8/2009. Disponível em <http:// www.cbro.org.br>. 2009. Acesso em: 20 jul. 2010.

DASZAK, P.; CUNNINGHAM, A. A.; HYATT, A. D. Emerging infectious diseases of wildlife threats to biodiversity and human health. Science, v. 287, n. 1, p. 443-448, 2000.

DE CASTRO, F.; BOLKER, B. Mechanisms of disease-induced extinction. Ecology Letters, v. 8, n. 1, p. 117-126, 2005.

FERREIRA, C. S.; FERREIRA, M. U.; NOGUEIRA, M. R. The prevalence of infection by intestinal parasites in urban slum in São Paulo, Brazil. Journal of Tropical Medicine and Hygiene, v. 97, n. 1, p. 121-127, 1994.

FREITAS, M. F. L.; OLIVEIRA, J. B.; CAVALCANTI, M. D. B.; LEITE, A. D.; MAGALHÃES, V. S.; OLIVEIRA, R. A.; SOBRINHO, A. E. Parasitos gastrointestinales de aves silvestres en cativeiro en el estado de Pernambuco, Brasil. Parasitología Latinoamericana, v. 57, n. 1-2, p. 50-54, 2002.

GRACZYK, T. K.; MAJEWSKA, A. C.; SCHWAB, K. J. The role of birds in dissemination of human waterborne enteropathogens. Trends in Parasitology, v. 24, n. 2, p. 55-59, 2008.

KIRWAN, G. M.; M. BARNETT, J.; MINNS, J. Significant ornithological observations from the Rio São Francisco valley, Minas Gerais, Brazil, with notes on conservation and biogeography. Ararajuba, v. 9, n. 1, p. 145-161, 2001.

LEDERBERG, J. Emerging infectious: an evolutionary perspective. Emerging infectious Diseases, v. 4, n. 3, p. 366-371, 1998.

LÓPEZ G.; FIGUEROLA, J.; SORIGUER, R. Time of day, age and feeding habits influence coccidian oocyst shedding in wild passerines. International Journal for Parasitology, v. 37, n. 5, p. 559-564, 2007.

MARIETTO GONÇALVES, G. A.; MARTINS, T. F.; LIMA, E. T.; LOPES, R. S.; ANDREATTI FILHO, R. L. Prevalência de endoparasitas em amostras fecais de aves silvestres e exóticas examinadas no Laboratório de Ornitopatologia e no Laboratório de Enfermidades Parasitárias da FMVZ-UNESP/Botucatu-SP. Ciência Animal Brasileira, v. 10, n. 1, p. 349-354, 2009.

MATHEWS, F. Chapter 8 zoonoses in wildlife: integrating ecology into management. Advances in Parasitology, v. 68, n. 1, p. 185-209, 2009.

McCALlUM, H.; DOBSON, A. Disease, habitat fragmentation and conservation. Proceedings Biological Sciences, v. 269, n. 1, p. 2041-2049, 2002. 
PORTO G. R.; A. PIRATELLI. Etograma da maria-preta, Molothrus bonariensis (Gmelin) (Aves, Emberizidae, Icterinae). Revista Brasileira de Zoologia, v. 22, n. 2, p. 306-312, 2005.

REED, K. D.; MEECE, J. K.; HENKEL, J. S.; SHUKLA, S. K. Birds, migration and emerging zoonoses: west nile virus, lyme disease, influenza A and enteropathogens. Clinical Medicine and Research, v. 1, n. 1, p. 5-12, 2003.

SIH, A.; JOHNSON, B. G.; LUIKART, G. Habitat loss: ecological evolutionary and genetic consequences. Trends in Ecology and Evolution, v. 15, n. 1, p. 132-134, 2000.

SLEEMAN, J. Wildlife zoonoses for the veterinary practitioner. Journal of Exotic Pet Medicine, v. 15, n. 1, p. 25-32, 2006.
SLIFKO, T. R.; SMITH, H. V.; ROSE, J.B. Emerging parasite zoonoses associated with water and food. International Journal for Parasitology, v. 30, n. 12-13, p. 1379-1393, Nov. 2000.

SMITH, K. F.; D. F. SAX; K. D. LAFFERTY. Evidence for the role of infectious disease in species extinction and endangerment. Conservation Biology, v. 20, n. 5, p. 1349-1357, 2006.

VALADÃO, R. M; MARÇAL JÚNIOR, O.; FRANCHIN, A. G. A avifauna no parque municipal Santa Luzia, zona urbana de Uberlândia, Minas Gerais. Bioscience Journal, v. 22, n. 2, p. 97-108, 2006.

VILLANUEVA, R. E. V.; SILVA, M. Organização trófica da avifauna do Campus da Universidade Federal de Santa Catarina (UFSC), Florianópolis, SC. Biotemas, v. 9, n. 2, p. 57-69, 1996. 